\title{
The metabolic syndrome of $\omega 3$-depleted rats. VI. Intestinal phospholipid saturated and monodesaturated fatty acids
}

\author{
YVON A. CARPENTIER, MIRJAM HACQUEBARD, LAURENCE PORTOIS and WILLY J. MALAISSE
}

Laboratory of Experimental Surgery, Université Libre de Bruxelles, 808 Route de Lennik, B-1070 Brussels, Belgium

Received August 21, 2009; Accepted October 2, 2009

DOI: 10.3892/ijmm_00000328

\begin{abstract}
Exposure of normal rats for 3-7 months to an $\omega 3$-deprived diet and subsequent exposure to an $\omega 3$-enriched diet were recently proposed as a model to study the metabolic consequences of alteration in the dietary supply of 13 PUFA and their time course. The same animal model was used in the present study, which aimed at characterizing the pattern of saturated and monodesaturated fatty acids in the phospholipids of the duodenum, jejunum, caecum and colon. With one exception (C18:0), the weight content of these fatty acids was lower in the proximal than distal intestinal segments, a situation possibly accounted for by the generation of shortchain fatty acids by the colonic flora and the resulting synthesis of longer fatty acids in colonocytes. The relative weight content of the 8 fatty acids under consideration

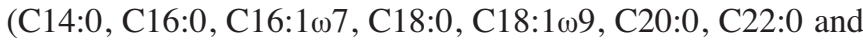
$\mathrm{C} 24: 0)$ was higher in the phospholipids of $\omega 3$-deprived rats, as compared to control animals. Exposure of either the control animals or 133 -deprived rats for 2-4 weeks to diets containing twice more lipids than the control or $\omega 3$-deprived diet given theretofore further increased, as a rule, the relative content of phospholipids in the saturated or monodesaturated fatty acids, such an increase being much more pronounced in the proximal segments of the intestinal tract than in the distal ones. A significant inverse correlation between the phospholipid content in C22:6w3 and saturated and monodesaturated fatty acids was only observed in the caecum and colon.
\end{abstract}

\section{Introduction}

In the two preceding reports in this series, the relative weight content of long-chain polyunsaturated $\omega 3$ and $\omega 6$ fatty acids in the phospholipids of the duodenum, jejunum, caecum and

Correspondence to: Professor W.J. Malaisse, Laboratory of Experimental Surgery, Université Libre de Bruxelles, 808 Route de Lennik, B-1070 Brussels, Belgium

E-mail:malaisse@ulb.ac.be

Key words: $\omega 3$-depleted rats, intestinal phospholipids, saturated and monodesaturated fatty acids colon was examined in 8 groups of 5-6 female rats each, including animals exposed from the seventh week after birth and for the following 3 or 7 months to either a control (5\% soybean oil) or an $\omega 3$-deprived $(5 \%$ sunflower oil) diet $(1,2)$. The time course for the repletion of $\omega 3$ fatty acids in the intestinal phospholipids was also investigated by exposing the $\omega 3$-deficient rat for 2 to 4-5 weeks to a flaxseed oilenriched diet (5\% sunflower oil, 5\% flaxseed oil). For the sake of comparison, the control rats were also given access for 4-5 weeks to either a soybean (10\% soybean oil) or flaxseed (5\% soybean oil, $5 \%$ flaxseed oil) oil-enriched diet. The present report extends this information to the saturated and monodesaturated fatty acids identified in the intestinal phospholipids of these 8 groups of rats.

\section{Materials and methods}

The 8 groups of 5-6 female rats each were the same as those indicated in our first report in this series (3). Briefly, 4 of these groups included control rats exposed for 3 or 7 months to a diet containing $5 \%(\mathrm{wt} / \mathrm{wt})$ soybean oil and then given access for 4-5 weeks to the same diet enriched with either another $5 \%$ of soybean oil or $5 \%$ of flaxseed oil. The other 4 groups consisted of rats exposed for 3 or 7 months to a diet containing 5\% sunflower oil and then given access for 2 or 4-5 weeks to the same diet enriched with $5 \%$ flaxseed oil. The fatty acid composition of these diets and the modalities of sacrifice and tissue sampling were also described in our prior publication (3). The small and large bowel segments were removed from mesenteric and vascular connections and sequentially removed from the peritoneum. Segments used for intestinal mucosa fatty acid analysis were the duodenum ( $5 \mathrm{~cm}$ distal to the pylorus), jejunum $(20 \mathrm{~cm}$ distal from duodenum), caecum and colon (segment between caecum and rectum). The lumen of each intestinal segment was thoroughly flushed with ice-cold $9 \mathrm{~g} \mathrm{NaCl} / 1$ to clear intestinal contents. Intestinal segments were then split lengthwise and the mucosa was gently scraped. Mucosal samples were immediately immersed in liquid nitrogen and stored at $-80^{\circ} \mathrm{C}$ for fatty acid analyses. The lipids were extracted (4), separated by thin-layer chromatography (5), and their fatty acid pattern determined by gas-liquid chromatography (6).

The present experiments were conducted in accordance with the principles of the Animal Experimentation Ethics Committee of Brussels Free University Medical School and approved by this Committee. 


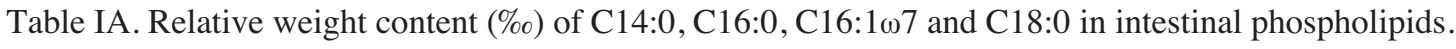

\begin{tabular}{|c|c|c|c|c|c|}
\hline Rats & Intestinal segment(s) & $\mathrm{C} 14: 0$ & C16:0 & $\mathrm{C} 16: 1 \omega 7$ & C18:0 \\
\hline \multirow[t]{3}{*}{$3 \mathrm{mC}$} & Duodenum and jejunum & $2.1 \pm 0.2(6)$ & $171.2 \pm 4.7(6)$ & $2.6 \pm 0.1(6)$ & $181.5 \pm 2.4(6)$ \\
\hline & Caecum & $6.6 \pm 0.4(6)$ & $296.9 \pm 5.7(6)$ & $6.1 \pm 0.3(6)$ & $124.5 \pm 6.1(6)$ \\
\hline & Colon & $8.8 \pm 1.1(6)$ & $210.3 \pm 6.9(6)$ & $8.1 \pm 1.3(6)$ & $121.3 \pm 10.7(6)$ \\
\hline \multirow[t]{3}{*}{$3 \mathrm{mD}$} & Duodenum + jejunum & $3.9 \pm 0.4(6)$ & $187.4 \pm 2.3(6)$ & $3.8 \pm 0.4(6)$ & $186.1 \pm 3.1(6)$ \\
\hline & Caecum & $10.2 \pm 1.8(6)$ & $209.3 \pm 7.0(6)$ & $14.0 \pm 2.6(6)$ & $173.1 \pm 10.3(6)$ \\
\hline & Colon & $11.3 \pm 0.6(6)$ & $258.1 \pm 23.4(6)$ & $11.5 \pm 1.3(6)$ & $135.8 \pm 5.5(6)$ \\
\hline \multirow[t]{4}{*}{$7 \mathrm{mC}$} & Duodenum & $4.6 \pm 0.0(3)$ & $182.6 \pm 6.1(3)$ & $3.6 \pm 0.3(3)$ & $189.5 \pm 1.5(3)$ \\
\hline & Jejunum & $3.3 \pm 0.5(5)$ & $185.9 \pm 3.7(5)$ & $3.9 \pm 0.4(5)$ & $175.6 \pm 4.6(5)$ \\
\hline & Caecum & $9.1 \pm 1.8(5)$ & $209.3 \pm 3.8(5)$ & $6.8 \pm 0.3(5)$ & $125.0 \pm 4.7(5)$ \\
\hline & Colon & $9.9 \pm 1.2(5)$ & $235.9 \pm 9.5(5)$ & $8.4 \pm 1.2(5)$ & $124.6 \pm 9.2(5)$ \\
\hline \multirow[t]{4}{*}{$7 \mathrm{mD}$} & Duodenum & $3.6 \pm 0.3(6)$ & $175.6 \pm 5.3(6)$ & $3.5 \pm 0.1(6)$ & $201.9 \pm 6.0(6)$ \\
\hline & Jejunum & $2.8 \pm 0.2(6)$ & $177.8 \pm 11.1(6)$ & $2.9 \pm 0.2(6)$ & $197.8 \pm 4.8(6)$ \\
\hline & Caecum & $16.4 \pm 5.2(6)$ & $219.7 \pm 8.4(6)$ & $14.4 \pm 2.6(6)$ & $137.6 \pm 11.9(6)$ \\
\hline & Colon & $12.0 \pm 1.4(6)$ & $268.3 \pm 16.2(6)$ & $11.3 \pm 1.1(6)$ & $131.9 \pm 3.9(6)$ \\
\hline \multirow[t]{4}{*}{$7 \mathrm{mC} / 4 \mathrm{wS}$} & Duodenum & $6.7 \pm 1.4(6)$ & $232.8 \pm 12.4(6)$ & $3.2 \pm 0.3(5)$ & $169.0 \pm 8.0(6)$ \\
\hline & Jejunum & $6.2 \pm 1.6(6)$ & $246.7 \pm 12.1(6)$ & N.D. & $174.7 \pm 6.2(6)$ \\
\hline & Caecum & $8.9 \pm 2.2(6)$ & $216.7 \pm 3.1(6)$ & N.D. & $133.0 \pm 4.1(6)$ \\
\hline & Colon & $18.3 \pm 4.8(6)$ & $264.4 \pm 11.4(6)$ & $5.9 \pm 0.6(6)$ & $126.8 \pm 2.7(6)$ \\
\hline \multirow[t]{4}{*}{$7 \mathrm{mC} / 4 \mathrm{wF}$} & Duodenum & $8.9 \pm 2.4(6)$ & $230.3 \pm 6.1(6)$ & $7.9 \pm 1.2(3)$ & $170.4 \pm 3.8(6)$ \\
\hline & Jejunum & $6.6 \pm 1.6(6)$ & $217.9 \pm 1.0(6)$ & N.D. & $186.1 \pm 6.2(6)$ \\
\hline & Caecum & $6.1 \pm 1.3(6)$ & $211.3 \pm 7.4(6)$ & $6.6 \pm 1.0(6)$ & $139.2 \pm 8.3(6)$ \\
\hline & Colon & $9.8 \pm 0.9(6)$ & $247.1 \pm 16.8(6)$ & $7.7 \pm 0.2(6)$ & $133.8 \pm 11.1(6)$ \\
\hline \multirow[t]{4}{*}{$7 \mathrm{mD} / 2 \mathrm{wF}$} & Duodenum & $5.5 \pm 0.7(6)$ & $211.8 \pm 14.3(6)$ & $5.3 \pm 0.6(5)$ & $171.7 \pm 4.5(6)$ \\
\hline & Jejunum & $5.9 \pm 0.3(6)$ & $210.4 \pm 7.4(6)$ & N.D. & $196.3 \pm 3.1(6)$ \\
\hline & Caecum & $1.5 \pm 0.6(3)$ & $220.2 \pm 1.0(6)$ & $10.5 \pm 1.9(6)$ & $130.1 \pm 7.7(6)$ \\
\hline & Colon & $7.2 \pm 1.5(6)$ & $234.1 \pm 20.4(6)$ & $9.8 \pm 1.1(6)$ & $113.7 \pm 1.6(6)$ \\
\hline \multirow[t]{4}{*}{$7 \mathrm{mD} / 4 \mathrm{wF}$} & Duodenum & $14.3 \pm 3.4(6)$ & $251.4 \pm 9.4(6)$ & $10.4 \pm 1.7(5)$ & $166.2 \pm 11.5(6)$ \\
\hline & Jejunum & $7.2 \pm 0.7(6)$ & $237.7 \pm 7.6(6)$ & $6.0 \pm 2.4(2)$ & $179.0 \pm 12.0(6)$ \\
\hline & Caecum & $7.4 \pm 0.6(6)$ & $214.8 \pm 9.4(6)$ & $8.4 \pm 1.7(6)$ & $125.1 \pm 5.0(6)$ \\
\hline & Colon & $10.1 \pm 0.5(6)$ & $245.4 \pm 8.7(6)$ & $10.0 \pm 2.2(6)$ & $127.2 \pm 4.6(6)$ \\
\hline
\end{tabular}

N.D., Not detected.

In the tables, the following symbols are used: $3 \mathrm{mC}$ and $7 \mathrm{mC}$ for the control rats examined 3 and 7 months after the onset of the present experiments, $3 \mathrm{mD}$ and $7 \mathrm{mD}$ for the $\omega 3$ depleted rats $(\omega 3 \mathrm{D})$ also examined 3 and 7 months after the start of the experiments, $7 \mathrm{mC} / 4 \mathrm{wS}$ and $7 \mathrm{mC} / 4 \mathrm{wF}$ for the control rats eventually exposed for 4-5 weeks to either the soybean $(\mathrm{S})$ or flaxseed $(\mathrm{F})$ oil-enriched diets, and $7 \mathrm{mD} / 2 \mathrm{wF}$ and $7 \mathrm{mD} / 4 \mathrm{wF}$ for the $\omega 3 \mathrm{D}$ rats eventually exposed for 2 or 4-5 weeks to the flaxseed oil-enriched diet (Table IA and B).

All results are presented as mean values $( \pm$ SEM) together with either the number of individual determinations (n) or degree of freedom (df). The statistical significance of differences between mean values was assessed using Student's t-test and confirmed by variance analysis with Bonferroni posttest. Null values were ignored.

\section{Results}

Saturated fatty acid content of intestinal phospholipids. No C6:0, C8:0, C10:0 or C12:0 was detected in any of the 174 samples examined in this study.

The C14:0 relative weight content of intestinal phospholipids was, as a rule, lower in the duodenum and jejunum than in the caecum or colon. For instance, in the control animals examined during the first 7 months of the present experiments, it averaged $3.08 \pm 0.33 \%$ o $(n=14)$ in the duodenum and jejunum, as distinct $(\mathrm{p}<0.001)$ from $7.72 \pm 0.91$ and $9.29 \pm 0.80 \%$ o $(n=11$ in both cases) in the caecum and colon, respectively (Fig. 1). Over the same period of 7 months, the C14:0 relative content of intestinal phospholipids averaged in the $\omega 3 \mathrm{D}$ rats $132.9 \pm 10.9 \%$ $(n=42 ; p<0.01)$ of the mean corresponding values recorded at 


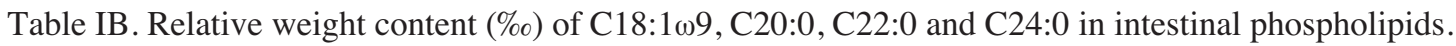

\begin{tabular}{|c|c|c|c|c|c|}
\hline Rats & Intestinal segment(s) & 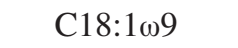 & C20:0 & $\mathrm{C} 22: 0$ & $\mathrm{C} 24: 0$ \\
\hline \multirow[t]{3}{*}{$3 \mathrm{mC}$} & Duodenum and jejunum & $54.1 \pm 2.2(6)$ & $5.6 \pm 1.0(6)$ & $6.5 \pm 0.9(6)$ & $5.7 \pm 0.7(6)$ \\
\hline & Caecum & $87.2 \pm 4.6(5)$ & $8.1 \pm 1.1(6)$ & $8.0 \pm 0.8(6)$ & $6.9 \pm 0.7(6)$ \\
\hline & Colon & $113.4 \pm 7.2(6)$ & $12.6 \pm 1.7(6)$ & $13.4 \pm 2.0(6)$ & $11.1 \pm 1.9(6)$ \\
\hline \multirow[t]{3}{*}{$3 \mathrm{mD}$} & Duodenum + jejunum & $79.6 \pm 2.9(6)$ & $11.4 \pm 0.6(6)$ & $11.3 \pm 0.4(6)$ & $8.3 \pm 0.2(6)$ \\
\hline & Caecum & $94.4 \pm 4.0(6)$ & $13.1 \pm 0.8(6)$ & $11.4 \pm 0.7(6)$ & $10.2 \pm 1.1(6)$ \\
\hline & Colon & $128.2 \pm 4.8(6)$ & $20.6 \pm 4.8(6)$ & $20.1 \pm 3.6(6)$ & $14.5 \pm 2.9(6)$ \\
\hline \multirow[t]{4}{*}{$7 \mathrm{mC}$} & Duodenum & $62.3 \pm 1.5(3)$ & $8.0 \pm 0.6(3)$ & $9.9 \pm 1.0(3)$ & $8.8 \pm 1.2(3)$ \\
\hline & Jejunum & $52.7 \pm 3.3(5)$ & $6.6 \pm 0.6(5)$ & $7.2 \pm 0.7(5)$ & $5.6 \pm 0.8(5)$ \\
\hline & Caecum & $95.3 \pm 4.2(5)$ & $9.0 \pm 0.4(5)$ & $8.8 \pm 0.2(5)$ & $11.1 \pm 3.1(5)$ \\
\hline & Colon & $107.1 \pm 10.8(5)$ & $13.2 \pm 1.5(5)$ & $13.1 \pm 1.0(5)$ & $10.7 \pm 0.6(5)$ \\
\hline \multirow[t]{4}{*}{$7 \mathrm{mD}$} & Duodenum & $70.4 \pm 1.8(6)$ & $8.1 \pm 0.5(6)$ & $9.8 \pm 0.4(6)$ & $8.4 \pm 0.5(6)$ \\
\hline & Jejunum & $66.1 \pm 2.5(6)$ & $9.3 \pm 2.3(6)$ & $10.0 \pm 1.6(6)$ & $9.1 \pm 1.8(6)$ \\
\hline & Caecum & $103.2 \pm 12.0(6)$ & $11.1 \pm 1.8(6)$ & $11.8 \pm 1.9(6)$ & $10.5 \pm 2.2(5)$ \\
\hline & Colon & $114.7 \pm 4.3(6)$ & $16.1 \pm 2.1(6)$ & $16.3 \pm 1.7(6)$ & $11.8 \pm 1.3(6)$ \\
\hline \multirow[t]{4}{*}{$7 \mathrm{mC} / 4 \mathrm{wS}$} & Duodenum & $63.1 \pm 1.8$ & $12.9 \pm 1.7(6)$ & $12.9 \pm 1.9(6)$ & $15.2 \pm 2.1(6)$ \\
\hline & Jejunum & $58.9 \pm 1.8(6)$ & $21.2 \pm 2.0(6)$ & $18.6 \pm 1.9(6)$ & $17.8 \pm 2.0(6)$ \\
\hline & Caecum & $88.5 \pm 3.4(6)$ & $11.1 \pm 0.9(6)$ & $9.9 \pm 1.6(6)$ & $8.4 \pm 0.6(6)$ \\
\hline & Colon & $108.5 \pm 3.6(6)$ & $17.3 \pm 1.3(6)$ & $17.2 \pm 0.9(6)$ & $11.6 \pm 0.6(6)$ \\
\hline \multirow[t]{4}{*}{$7 \mathrm{mC} / 4 \mathrm{wF}$} & Duodenum & $68.4 \pm 2.1(6)$ & $14.0 \pm 1.0(6)$ & $14.3 \pm 1.1(6)$ & $16.4 \pm 1.5(6)$ \\
\hline & Jejunum & $57.9 \pm 3.3(6)$ & $16.8 \pm 0.9(6)$ & $14.6 \pm 1.0(6)$ & $14.5 \pm 1.6(6)$ \\
\hline & Caecum & $91.2 \pm 3.4(6)$ & $11.1 \pm 1.3(6)$ & $10.7 \pm 1.1(6)$ & $9.2 \pm 1.1(6)$ \\
\hline & Colon & $109.3 \pm 6.1(6)$ & $20.5 \pm 2.8(6)$ & $18.8 \pm 2.3(6)$ & $15.7 \pm 2.0(6)$ \\
\hline \multirow[t]{4}{*}{$7 \mathrm{mD} / 2 \mathrm{wF}$} & Duodenum & $75.9 \pm 4.0(6)$ & $11.6 \pm 1.4(6)$ & $12.3 \pm 1.4(6)$ & $13.2 \pm 1.6(6)$ \\
\hline & Jejunum & $68.3 \pm 1.2(6)$ & $18.2 \pm 1.5(6)$ & $16.2 \pm 1.0(6)$ & $13.1 \pm 0.9(6)$ \\
\hline & Caecum & $105.0 \pm 2.9(6)$ & $14.9 \pm 1.8(6)$ & $14.5 \pm 1.5(6)$ & $13.0 \pm 1.9(6)$ \\
\hline & Colon & $120.6 \pm 4.7(6)$ & $19.4 \pm 5.4(6)$ & $17.9 \pm 3.4(6)$ & $13.0 \pm 2.9(6)$ \\
\hline \multirow[t]{4}{*}{$7 \mathrm{mD} / 4 \mathrm{wF}$} & Duodenum & $75.5 \pm 3.2(6)$ & $16.6 \pm 0.3(6)$ & $17.2 \pm 2.8(6)$ & $20.8 \pm 3.6(6)$ \\
\hline & Jejunum & $66.3 \pm 2.6(6)$ & $26.1 \pm 1.1(6)$ & $24.1 \pm 1.5(6)$ & $25.0 \pm 1.8(6)$ \\
\hline & Caecum & $98.7 \pm 2.7(6)$ & $12.3 \pm 3.1(6)$ & $17.3 \pm 3.5(6)$ & $13.1 \pm 1.4(6)$ \\
\hline & Colon & $118.3 \pm 6.7(6)$ & $19.1 \pm 2.2(6)$ & $19.9 \pm 1.2(6)$ & $14.7 \pm 1.8(6)$ \\
\hline
\end{tabular}

the same age and at the same intestinal level in the control animals $(100.0 \pm 4.5 \%$; $=36)$. Even when including in such a comparison the results found in the control animals and $\omega 3 \mathrm{D}$ rats examined after 4-5 weeks exposure to a flaxseed oilenriched diet, the difference between $\omega 3 \mathrm{D}$ rats $(129.8 \pm 7.9 \%$; $\mathrm{n}=66)$ and control animals $(100.0 \pm 4.8 \% ; \mathrm{n}=60)$ remained highly significant $(\mathrm{p}<0.007)$, despite the fact that in the rats exposed for 4-5 weeks to the flaxseed oil-enriched diet, the difference between $\omega 3 \mathrm{D}$ rats $(124.2 \pm 10.7 \% ; \mathrm{n}=24)$ and control animals $(100.0 \pm 10.1 \% ; n=24)$ failed to achieve statistical significance $(\mathrm{p}>0.1)$. When the control animals were exposed for 4-5 weeks to the soybean oil-enriched diet, the C14:0 content of intestinal phospholipids increased $(\mathrm{p}<0.04)$ to $153.9 \pm 20.1 \%(\mathrm{n}=24)$ of the mean corresponding values found at the same intestinal level shortly before such an exposure $(100.0 \pm 7.2 \% ; n=18)$. In both the control animals and $\omega 3 \mathrm{D}$ rats exposed for 4-5 weeks to the flaxseed oil-enriched diet, the C14:0 content of phospholipids was also increased $(\mathrm{p}<0.001)$ in the duodenum and jejunum, averaging $261.7 \pm 33.2 \%(n=24)$ of the mean corresponding values found at the same intestinal levels shortly before such an exposure $(100.0 \pm 4.5 \% ; n=20)$. Such a difference was not observed in the caecum or colon, however, the results recorded after exposure to the flaxseed oil-enriched diet averaging no more than $74.1 \pm 5.9 \%(n=24 ; \mathrm{p}<0.03)$ of the mean corresponding values $(100.0 \pm 9.9 \% ; n=22)$ found before exposure to the flaxseed oil-enriched diet in the same type of rats (control or $\omega 3 \mathrm{D}$ ) and at the same intestinal level (caecum or colon).

The results recorded in the case of C16:0 were, in several respects, comparable to those found for the C14:0. First, in the control animals, the $\mathrm{C} 16: 0$ relative weight content of phospholipids was lower $(\mathrm{p}<0.001)$ in the duodenum and jejunum $(17.9 \pm 0.3 \% ; n=14)$ than in either the caecum 

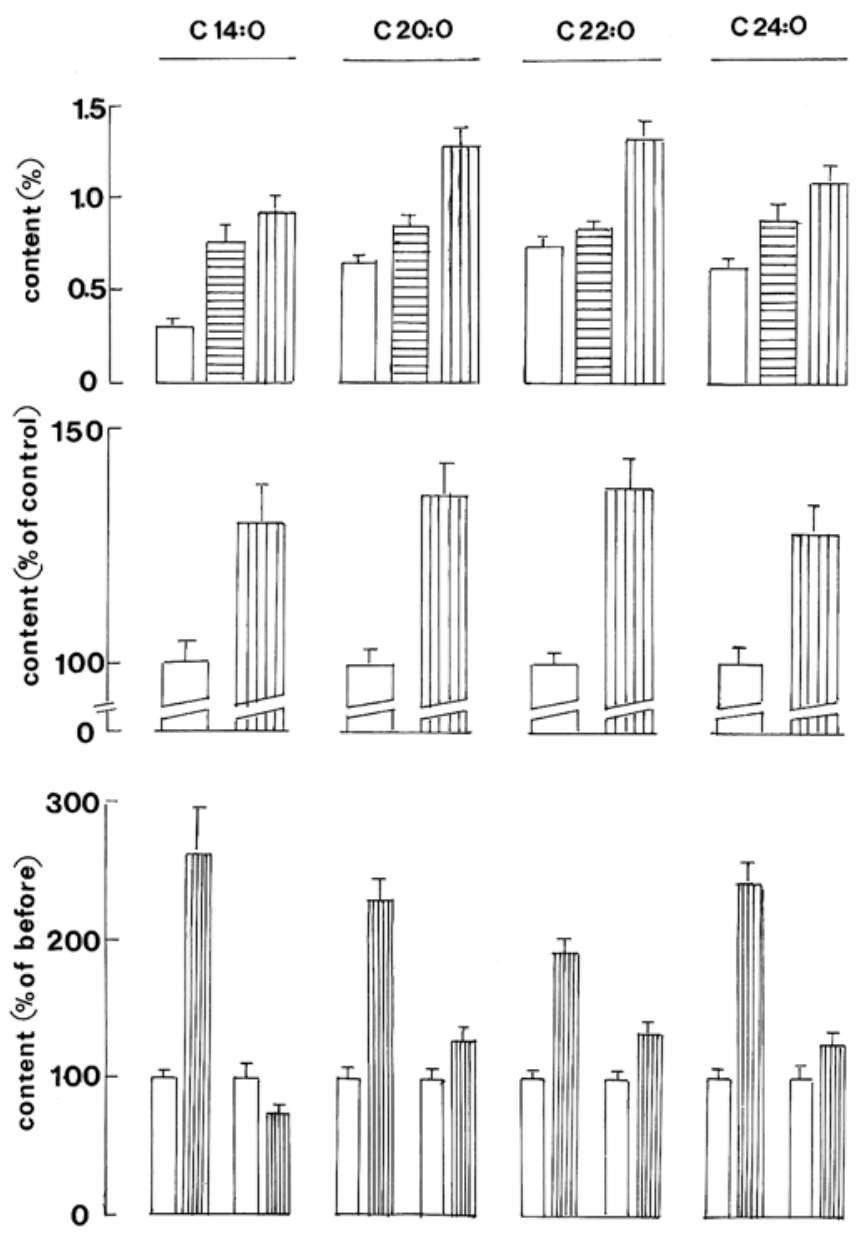

Figure 1. Relative weight content of four saturated fatty acids in intestinal phospholipids. Upper panel: values recorded in the duodenum and jejunum (open columns), caecum (horizontally hatched columns) or colon (vertically hatched columns) of control animals examined during the first 7 months of the present experiments; mean values $( \pm$ SEM) refer to 14 (duodenum and jejunum) or 11 (caecum or colon) individual measurements. Middle panel: values recorded in $\omega 3 \mathrm{D}$ rats (vertically hatched columns) and expressed relative to the mean corresponding values found at the same age and same intestinal location in control animals (open columns); mean values ( \pm SEM) refer to 60 (control animals) or 66 ( $\omega 3 \mathrm{D}$ rats) individual measurements collected during the first 7 months of the present experiments and after 4-5 weeks exposure to a flaxseed oil-enriched diet. Lower panel: values recorded in both control animals and $\omega 3 \mathrm{D}$ rats before (open columns) and after 4-5 weeks exposure to a flaxseed oil-enriched diet (vertically hatched columns); mean values ( \pm SEM) refer to 20-22 (open columns) or 24 (hatched columns) individual measurements made in either the duodenum and jejunum (left pairs of columns) or caecum and colon (right pairs of columns), and expressed relative to the mean corresponding values recorded at the same intestinal level and in the same type of rats (control or $\omega 3 \mathrm{D}$ ) shortly before exposure to the flaxseed oil-enriched diet.

$(20.8 \pm 0.3 \% ; n=11)$ or colon $(22.2 \pm 0.7 \% ; n=11)$, which yielded mean values comparable to one another $(\mathrm{p}>0.8)$. Second, despite the fact that the values recorded in $\omega 3 \mathrm{D}$ rats often failed to differ significantly from those found in control animals of the same age and at the same intestinal level, the results recorded in $\omega 3 \mathrm{D}$ rats during the first 7 months of the present experiments were nevertheless significantly higher $(\mathrm{p}<0.05)$ than those found in control animals, averaging 106.3 $\pm 2.5 \%$ $(n=42)$ of the mean corresponding values found at the same age and intestinal level in the latter animals (100.0 $1.0 \%$; $\mathrm{n}=36$ ). Such a difference became even more significant $(\mathrm{p}<0.007)$ after inclusion of the results obtained in the control and $\omega 3 \mathrm{D}$ rats exposed for 4-5 weeks to the flaxseed oilenriched diet, the pooled data averaging 105.8 $\pm 1.8 \% \quad(n=66)$ in $\omega 3 \mathrm{D}$ rats, as compared to $100.0 \pm 1.1 \%(n=60)$ in the control animals. Third, when the control rats were exposed to either the soybean or flaxseed oil-enriched diet, the C16:0 relative weight content increased, in the duodenum and jejunum, from $18.5 \pm 0.8 \%(\mathrm{n}=8)$ to respectively $24.0 \pm 0.9 \%(\mathrm{n}=12 ; \mathrm{p}<0.001)$ and $22.4 \pm 0.6 \%(n=12 ; p<0.001)$, the latter two mean values failing to differ significantly $(p>0.1)$ from one another. Likewise, when the $\omega 3 \mathrm{D}$ rats were exposed to the flaxseed oil-enriched diet, the C16:0 content of duodenal and jejunal phospholipids increased from $17.7 \pm 0.6 \%$ to $21.1 \pm 0.8 \%$ ( $n=12$ in both cases; $\mathrm{p}<0.005)$ after 2 weeks and further increased $(\mathrm{p}<0.001)$ to $24.5 \pm 0.6 \%(\mathrm{n}=12)$ after $4-5$ weeks. In the caecum and colon, however, the $\mathrm{C} 16: 0$ relative content of phospholipids failed to differ significantly in either the control animals or $\omega 3 \mathrm{D}$ rats examined before and after exposure to a soybean or flaxseed oil-enriched diet (Fig. 2).

At variance with other saturated fatty acids, C18:0 displayed a higher relative weight content in the duodenal and jejunal phospholipids than in the caecal and colic ones. For instance, in the control rats, such a content averaged $18.1 \pm 0.2 \%(n=14)$ in the duodenum and jejunum, as distinct $(\mathrm{p}<0.001)$ from $12.5 \pm 0.4$ and $12.3 \pm 0.7 \%$ ( $\mathrm{n}=11$ in both cases) in the caecum and colon, respectively. The C18:0 relative content of intestinal phospholipids averaged, in the $\omega 3 \mathrm{D}$ rats, $112.7 \pm 2.6 \%(n=42 ; \mathrm{p}<0.001)$ of the mean corresponding values found at the same age and same intestinal location in the control animals $(100.0 \pm 1.9 \% ; n=36)$. Such a difference remained significant $(\mathrm{p}<0.025)$ even after inclusion of the results collected in the control animals and $\omega 3 \mathrm{D}$ rats exposed for 4-5 weeks to a flaxseed oil-enriched diet, with mean respective overall percentages of $100.0 \pm 1.5 \%(n=60)$ in control animals versus $106.1 \pm 2.2 \%(n=66)$ in $\omega 3 \mathrm{D}$ rats. When the control rats were exposed to either the soybean or flaxseed oil-enriched diet, no significant change in the C18:0 content was observed, the measurements averaging 99.2 \pm 2.1 and $103.7 \pm 3.2 \%$ ( $n=24$ in both cases), respectively, of the mean corresponding values recorded at the same intestinal level just before such exposures $(100.0 \pm 2.2 \% ; n=18)$. In the $\omega 3 \mathrm{D}$ rats exposed for 2 and 4-5 weeks to the flaxseed oil-enriched diet, the C18:0 content of intestinal phospholipids was decreased $(\mathrm{p}<0.06$ or less) respectively to $90.8 \pm 1.8$ and $90.0 \pm 2.5 \%$ ( $n=24$ in both cases) of the mean corresponding values found at the same intestinal level before such an exposure $(100.0 \pm 2.3 \%$; $n=24)$. In other words, after 4-5 weeks exposure to the flaxseed oil-enriched diet, the $\mathrm{C} 18: 0$ relative content of intestinal phospholipids was no more significantly different $(\mathrm{p}>0.1)$ in the $\omega 3 \mathrm{D}$ rats and control animals, averaging in the former rats $94.7 \pm 2.5 \%(n=24)$ of the mean corresponding values found at the same intestinal level in the control animals $(100.0 \pm 2.6 \% ; n=24)$. The results concerning C18:0 also differed from those obtained with C14:0, C16:0, $\mathrm{C} 16: 1 \omega 7, \mathrm{C} 18: 1 \omega 9, \mathrm{C} 20: 0, \mathrm{C} 22: 0$ or $\mathrm{C} 24: 0$ by the fact that, after 4-5 weeks exposure of either the control animals of $\omega 3 \mathrm{D}$ rats to a flaxseed oil-enriched diet, the $\mathrm{C} 18: 0$ relative content found in the duodenum and jejunum and expressed relative to the mean corresponding values recorded shortly before such an exposure $(92.2 \pm 2.8 \% ; n=24)$ was lower $(\mathrm{p}<0.04)$ than that 


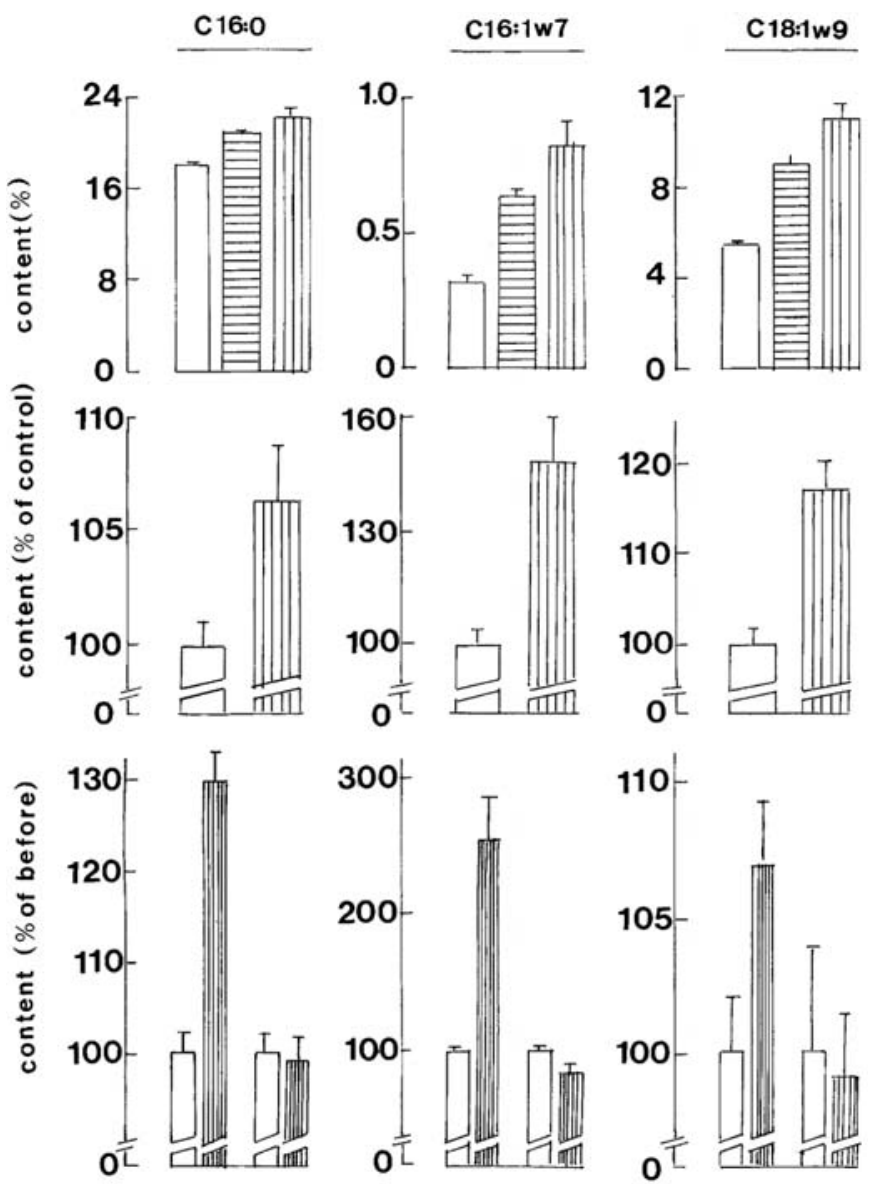

Figure 2. Relative weight content of C16:0, C16:1 $1 \omega 7$ and $\mathrm{C} 18: 1 \omega 9$ in intestinal phospholipids. Upper panel: values recorded in the duodenum and jejunum (open columns), caecum (horizontally hatched columns) or colon (vertically hatched columns) of control animals examined during the first 7 months of the present experiments; mean values $( \pm$ SEM) refer to 14 (duodenum and jejunum) or 11 (caecum or colon) individual measurements Middle panel: values recorded in $\omega 3 \mathrm{D}$ rats (vertically hatched columns) and expressed relative to the mean corresponding values found at the same age and same intestinal level in control animals (open columns); mean values $( \pm$ SEM) refer to 36 (control animals) or 42 ( $\omega 3 \mathrm{D}$ rats) individual measurements collected during the first 7 months of the present experiments. Lower panel: values recorded in both control animals and $\omega 3 \mathrm{D}$ rats before (open columns) and after 4-5 weeks exposure to a flaxseed oilenriched diet (vertically hatched columns); mean values $( \pm$ SEM) refer to 20-22 (open columns) or 10-24 (hatched columns) individual measurements made in either the duodenum and jejunum (left pairs of columns) or caecum and colon (right pairs of columns) and expressed relative to the mean corresponding values recorded at the same intestinal level and in the same type of rats (control or $\omega 3 \mathrm{D}$ ) shortly before exposure to the flaxseed oilenriched diet.

found in the caecum and colon $(101.5 \pm 3.3 \% ; n=24)$, only the first of these two percentages differing significantly $(\mathrm{p}<0.025)$ from the reference data collected before exposure to the flaxseed oil-enriched diet $(100.0 \pm 1.2 \%$; $\mathrm{n}=20)$.

The results obtained with the last three saturated fatty acids, i.e. C20:0, C22:0 and C24:0, were similar in all respects with those recorded in the case of C14:0 (Fig. 1). First, the phospholipid content of these fatty acids followed a duodenum and jejunum < caecum < colon hierarchy. For instance, in the control rats examined during the first 7 months of the present experiments, the C20:0 content of phospholipids was higher $(\mathrm{p}<0.025)$ in the caecum than duodenum and jejunum, and further increased $(\mathrm{p}<0.005)$ in the colon. The $\mathrm{C} 22: 0$ content of phospholipids was also significantly higher $(\mathrm{p}<0.001)$ in the colon than in the duodenum and jejunum or caecum. The C24:0 content of phospholipids was higher ( $p<0.04$ or less) in either the caecum or colon than in the duodenum and jejunum. Second, the relative weight content of C20:0, C22:0 and $\mathrm{C} 24: 0$ in the phospholipids of $\omega 3 \mathrm{D}$ rats exceeded that of control animals. Thus, the data recorded in the $\omega 3 \mathrm{D}$ rats averaged, for $\mathrm{C} 20: 0, \mathrm{C} 22: 0$ and $\mathrm{C} 24: 0$ respectively, $135.9 \pm 7.1 \%(n=66 ; p<0.001), 137.7 \pm 5.9 \%(n=66 ; p<0.001)$ and $128.0 \pm 6.2 \%(n=66 ; p<0.001)$ of the mean corresponding values found at the same intestinal level and same age in control animals $(100.0 \pm 3.3 \%, 100.0 \pm 2.9 \%$ and $100.0 \pm 3.8 \%$; $\mathrm{n}=60$ in all cases). Such an increase was already evident after only 3 months of dietary deprivation. For instance, in the duodenum and jejunum, the measurements made at that time in the $\omega 3 \mathrm{D}$ rats averaged for $\mathrm{C} 20: 0, \mathrm{C} 22: 0$ and $\mathrm{C} 24: 0$, respectively, $203.6 \pm 10.2,173.7 \pm 6.5$ and $146.3 \pm 4.2 \%$ ( $n=6$ and $\mathrm{p}<0.01$ or less) of the mean values found at the same age in the control animals $(100.0 \pm 17.3,100.0 \pm 14.5$ and $100.0 \pm 12.9 \%$; $\mathrm{n}=6$ in all cases). Last, after $4-5$ weeks exposure to a flaxseed oil-enriched diet, the increase in the phospholipid content of C20:0, C22:0 and C24:0, relative to the mean corresponding values found in either control animals or $\omega 3 \mathrm{D}$ rats examined shortly before such an exposure, was always higher in the duodenum and jejunum than in the caecum and colon. In the case of C20:0, such an increase averaged $129.4 \pm 16.9 \%(\mathrm{df}=42$; $\mathrm{p}<0.001)$ in the duodenum and jejunum, as distinct $(\mathrm{p}<0.001)$ of only $26.6 \pm 11.9 \%(\mathrm{df}=44 ; \mathrm{p}<0.05)$ in the caecum and colon. In the case of $\mathrm{C} 22: 0$, the increase averaged $90.8 \pm 13.2 \%$ $(\mathrm{df}=42 ; \mathrm{p}<0.001)$ in the duodenum and jejunum, as compared $(\mathrm{p}<0.001)$ to only $33.7 \pm 10.2 \%(\mathrm{df}=44 ; \mathrm{p}<0.005)$ in the caecum and colon. In the case of $\mathrm{C} 24: 0$, the increase averaged $141.9 \pm 17.7 \%(\mathrm{df}=42 ; \mathrm{p}<0.001)$ in the duodenum and jejunum versus only $25.8 \pm 13.3 \%(\mathrm{df}=44 ; \mathrm{p}<0.07)$ in the caecum and colon.

For the 4 saturated fatty acids considered in Fig. 1, the increase of their relative weight content in phospholipids was also more pronounced in the duodenum and jejunum than in the caecum and colon when the control rats were exposed for 4-5 weeks to the soybean oil-enriched diet. Thus, relative to the corresponding mean values found at the same intestinal level in the control animals examined shortly before such an exposure, the results averaged $211.9 \pm 14.6 \%(n=48)$ in the duodenum and jejunum, as distinct $(\mathrm{p}<0.001)$ from only $120.8 \pm 8.2 \%(n=48)$ in the caecum and colon. Likewise, when considering the results recorded in the $\omega 3 \mathrm{D}$ rats after only 2 weeks of exposure to the flaxseed oil-enriched diet, the intestinal phospholipid content of C14:0, C20:0, C22:0 and C24:0, expressed relative to the corresponding values recorded in the $\omega 3 \mathrm{D}$ rats shortly before such an exposure, was again higher $(\mathrm{p}<0.001)$ in the duodenum and jejunum $(161.3 \pm 6.3 \%$; $\mathrm{n}=48)$ than in the caecum and colon $(101.3 \pm 9.1 \% ; \mathrm{n}=48)$.

Monodesaturated fatty acid content of intestinal phospholipids. The two monodesaratured fatty acids $\mathrm{C} 16: 1 \omega 7$ and C18:1w9 yielded comparable results. First, in the control animals examined during the first 7 months of the present experiments, the relative weight content of both $\mathrm{C} 16: 1 \omega 7$ and C18:1w9 were higher $(p<0.001)$ in the caecum than in the 
duodenum and jejunum, and further increased ( $\mathrm{p}<0.05$ or less) in the colon (Fig. 2, upper panel). Second, over the same period, the values found in $\omega 3 \mathrm{D}$ rats were higher $(\mathrm{p}<0.001)$ than those recorded in the control animals, i.e. 148.3 \pm 11.7 and $117.4 \pm 3.0 \%$ ( $n=42$ in both cases), for $\mathrm{C} 16: 1 \omega 7$ and $\mathrm{C} 18: 1 \omega 9$, respectively, as compared to $100.0 \pm 3.9$ and $100.0 \pm 2.1 \% \quad(n=36$ in both cases) for the mean corresponding values found at the same intestinal level in control rats of the same age (Fig. 2, middle panel). Third, a comparable situation prevailed when considering the control animals and $\omega 3 \mathrm{D}$ rats exposed for $4-5$ weeks to a flaxseed oil-enriched diet. Thus, in the case of C16:1 $1 \omega 7$, the results recorded in $\omega 3 \mathrm{D}$ rats averaged $159.3 \pm 23.8 \%(\mathrm{n}=18 ; \mathrm{p}<0.05)$ of the mean corresponding values found at the same intestinal level in control animals $(100.0 \pm 15.3 \% ; n=18)$; in the case of $\mathrm{C} 18: 1 \omega 9$, the same percentages were $110.5 \pm 2.3 \%(\mathrm{n}=24 ; \mathrm{p}<0.003)$ in $\omega 3 \mathrm{D}$ rats versus $100.0 \pm 2.2 \%(\mathrm{n}=24)$ in control animals. Last, as documented in the lower panel of Fig. 2, in both control animals and $\omega 3 \mathrm{D}$ rats exposed for 4-5 weeks to the flaxseed oil-enriched diet, the content of duodenal and jejunal phospholipids in $\mathrm{C} 16: 1 \omega 7$ or $\mathrm{C} 18: 1 \omega 9$ was significantly higher $(\mathrm{p}<0.04$ or less) than that recorded in the same type of rats (control or $\omega 3 \mathrm{D}$ ) and at the same intestinal level shortly before such an exposure. In contrast, however, such was no more the case in the caecum or colon. The results collected in the caecum or colon and also expressed relative to the mean corresponding values found in the same type of rats and at the same intestinal level indeed failed to differ significantly from the latter values, whilst being significantly lower ( $p<0.04$ or less) than those collected in the duodenum and jejunum and expressed in the same manner (Fig. 2, lower panel). These findings are also similar to those made in the case of C16:0, as illustrated in Fig. 2, and other saturated fatty acids (see Fig. 1). At this point, it should be underlined that a comparable situation prevailed in the control animals exposed for 4-5 weeks to the soybean oil-enriched diet. For the three fatty acids considered in Fig. 2, the results recorded after exposure to the latter diet and expressed relative to the mean corresponding values found for the same fatty acid and at the same intestinal location shortly before such an exposure were indeed, once again, higher in the jejunum and duodenum than in the caecum and colon. They represented, in the caecum and colon, no more than $88.5 \pm 2.2 \%(n=30 ; p<0.001)$ of the mean corresponding values found for the same fatty acid in the duodenum and jejunum $(100.0 \pm 2.1 \% ; n=28)$. Likewise, when the $\omega 3 \mathrm{D}$ rats were exposed for only 2 weeks to the flaxseed oil-enriched diet, the same analytical procedure yielded, for the three fatty acids considered in Fig. 2, a mean value in the caecum and colon representing no more than $76.7 \pm 3.9 \%(n=36 ; p<0.001)$ of the mean corresponding values found in the duodenum and jejunum $(100.0 \pm 2.5 \%$; $n=29)$.

Ratio between selected fatty acids in intestinal phospholipids. The ratio between selected fatty acids in phospholipids also differed in distinct segments of the intestinal tract and in rats exposed to distinct diets.

For instance, the $\mathrm{C} 16: 1 \omega 7 / \mathrm{C} 16: 0$ ratio was lower in the duodenum and jejunum than in either the caecum or colon. In the control animals examined during the first 7 months of the present experiments, it averaged $1.84 \pm 0.11 \%(n=14)$ in the duodenum and jejunum, as distinct $(\mathrm{p}<0.001)$ from $3.06 \pm 1.27$ and $3.69 \pm 0.38 \%$ ( $n=11$ in both cases) in the caecum and colon, respectively. Over the same period, the results recorded in $\omega 3 \mathrm{D}$ rats averaged $139.7 \pm 11.0 \%(n=42 ; p<0.005)$ of the mean corresponding values found at the same age and same intestinal location in control rats $(100.0 \pm 3.6 \% ; n=36)$. Comparable results $(\mathrm{p}>0.7)$ were obtained when comparing $\omega 3 \mathrm{D}$ rats $(133.1 \pm 12.0 \% ; \mathrm{n}=16 ; \mathrm{p}<0.025)$ to control animals $(100.0 \pm 6.5 \% ; n=15)$, both exposed for $4-5$ weeks to a flaxseed oil-enriched diet. The $\mathrm{C} 16: 1 \omega 7 / \mathrm{C} 16: 0$ ratio in intestinal phospholipids was decreased, in the control rats exposed for 4-5 weeks to the soybean oil-enriched diet, to $66.7 \pm 4.8 \%(n=10 ; p<0.005)$ of the mean corresponding values found at the same intestinal level shortly before such an exposure $(100.0 \pm 8.5 \% ; n=8)$. The flaxseed oil-enriched diet, when offered for 4-5 weeks to either control animals or $\omega 3 \mathrm{D}$ rats, increased the $\mathrm{C} 16: 1 \omega 7 / \mathrm{C} 16: 0$ ratio in the duodenum and jejunum to $186.6 \pm 17.9 \%(n=10 ; p<0.001)$ of the mean corresponding values found at the same intestinal level and in the same type of rats (control or $\omega 3 \mathrm{D}$ ) shortly before such an exposure $(100.0 \pm 3.4 \% ; n=15)$, whilst failing to affect it significantly $(\mathrm{p}>0.3)$ in the caecum and colon $(90.9 \pm 7.0$ versus $100.0 \pm 6.0 \%$; $\mathrm{n}=22-23)$.

Likewise, in the control rats examined during the first 7

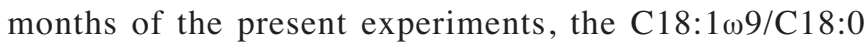
ratio was lower $(\mathrm{p}<0.001)$ in the duodenum and jejunum $(30.8 \pm 1.1 \% ; n=14)$ than in the caecum $(73.7 \pm 3.7 \% ; n=11)$, and further increased $(\mathrm{p}<0.05)$ in the colon $(94.3 \pm 8.1 \% ; \mathrm{n}=11)$. In the $\omega 3 \mathrm{D}$ rats, the $\mathrm{C} 18: 1 \omega 9 / \mathrm{C} 18: 0$ ratio averaged $109.7 \pm 3.2 \%$ $(n=66 ; p<0.02)$ of the mean corresponding values found at the same age and same intestinal level in control animals $(100.0 \pm 2.4 \% ; n=60)$. The relative magnitude of this increase in the $\mathrm{C} 18: 1 \omega 9 / \mathrm{C} 18: 0$ ratio $(9.7 \pm 4.0 \%$; df: 124$)$ was thus lower $(\mathrm{p}<0.005)$ than that recorded for the $\mathrm{C} 16: 1 \omega 7 / \mathrm{C} 16: 0$ ratio $(37.9 \pm 9.6 \% ; \mathrm{df}=107)$. When either the control animals or $\omega 3 \mathrm{D}$ rats were exposed for 2 to $4-5$ weeks to a soybean or

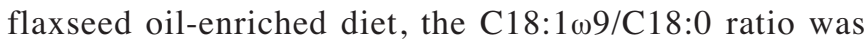
invariably increased in the duodenum and jejunum, to an overall mean value representing $116.9 \pm 3.0 \%(n=48 ; \mathrm{p}<0.002)$ of the mean corresponding value found in the same type of rats (control or odm3D) examined shortly before such an exposure $(100.0 \pm 3.0 \% ; n=20)$. According to the same analytical procedure, however, the results recorded in the caecum and colon only represented $99.0 \pm 2.6 \%(n=48 ; p>0.8)$ of their corresponding reference values $(100.0 \pm 5.2 \% ; n=22)$. In this respect, the difference between the results collected in the proximal (duodenum and jejunum) versus distal (caecum and colon) intestine remained significant $(\mathrm{p}<0.02)$ even when the calculation of the diet-related changes took into account the dispersion of results both before and after exposure to each diet, with mean values of $+16.9 \pm 5.1 \%(\mathrm{df}=66)$ at the proximal level and $-1.0 \pm 5.2 \%(\mathrm{df}=68)$ at the distal level.

The $(\mathrm{C} 18: 0+\mathrm{C} 18: 1 \omega 9) /(\mathrm{C} 16: 0+\mathrm{C} 16: 1 \omega 7)$ ratio, taken as representative of an elongase-catalyzed equilibrium, was much higher $(\mathrm{p}<0.001)$ in the duodenum and jejunum $(1.31 \pm 0.03$; $\mathrm{n}=14)$ than in either the caecum $(1.00 \pm 0.02 ; n=11)$ or colon $(1.02 \pm 0.04 ; \mathrm{n}=11)$, these results referring to the control animals examined during the first 7 months of the present experiments. Over the same period, this ratio averaged in the $\omega 3 \mathrm{D}$ rats $107.0 \pm 2.6 \%(n=42 ; p<0.03)$ of the mean corresponding 


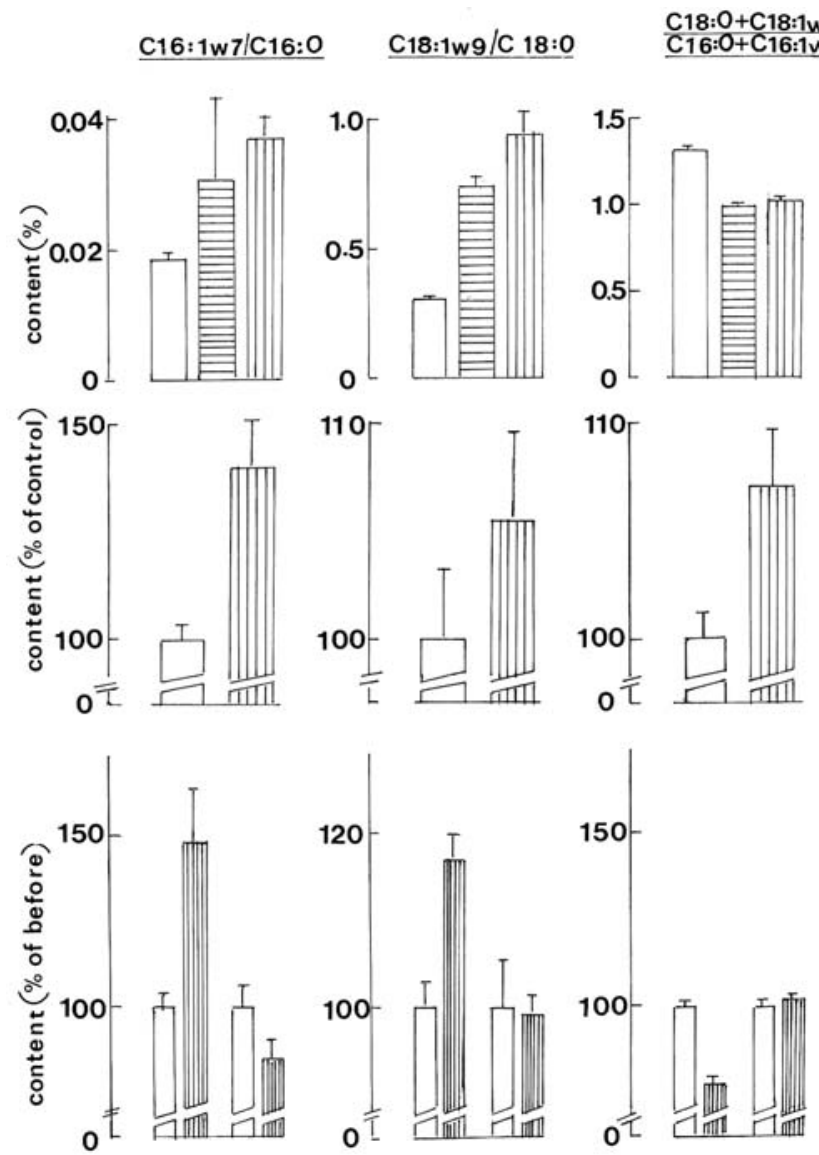

Figure 3. Ratio between selected fatty acids in intestinal phospholipids. Upper panel: values recorded in the duodenum and jejunum (open columns), caecum (horizontally hatched columns) or colon (vertically hatched columns) of control animals examined during the first 7 months of the present experiments; mean values $( \pm$ SEM) refer to 14 (duodenum and jejunum) or 11 (caecum or colon) individual measurements. Middle panel: values recorded in $\omega 3 \mathrm{D}$ rats (vertically hatched columns) and expressed relative to the mean corresponding values found at the same age and same intestinal level in control animals (open columns); mean values ( \pm SEM) refer to 36 (control animals) and 42 ( $\omega 3 \mathrm{D}$ rats) individual measurements collected during the first 7 months of the present experiments. Lower panel: values recorded in both control animals and $\omega 3 \mathrm{D}$ rats before (open columns) and after exposure to a soybean or flaxseed oil-enriched diet (vertically hatched columns); mean values ( \pm SEM) refer to 20-22 (open columns) and 19-48 (hatched columns) individual measurements made in either the duodenum and jejunum (left pairs of columns) or caecum and colon (right pairs of columns) and expressed relative to the mean corresponding values recorded at the same intestinal level and in the same type of rats (control or $\omega 3 \mathrm{D})$ shortly before exposure to these enriched diets.

values recorded at the same age and same intestinal level in control animals $(100.0 \pm 1.2 \% ; n=36)$. However, when the control animals and $\omega 3 \mathrm{D}$ rats were exposed for 4-5 weeks to a flaxseed oil-enriched diet, the values recorded in $\omega 3 \mathrm{D}$ rats represented no more than $94.1 \pm 2.5 \%(n=24 ; p>0.1)$ of the mean corresponding values found at the same intestinal levels in the control animals $(100.0 \pm 2.8 \%$; $=24)$. These findings indicate that exposure to the flaxseed oil-enriched diet restored comparable values for the $(\mathrm{C} 18: 0+\mathrm{C} 18: 1 \omega 9) /$ $(\mathrm{C} 16: 0+\mathrm{C} 16: 1 \omega 7)$ ratio in control and $\omega 3 \mathrm{D}$ rats. In the control animals eventually exposed to the soybean or flaxseed oilenriched diet, respectively, the $(\mathrm{C} 18: 0+\mathrm{C} 18: 1 \omega 9) /(\mathrm{C} 16: 0+$ $\mathrm{C} 16: 1 \omega 7)$ ratio decreased in the duodenum and jejunum to $77.5 \pm 4.6 \%(n=12 ; p<0.005)$ and $84.9 \pm 4.5 \%(n=12 ; p<0.02)$ of the mean corresponding values recorded at the same intestinal level in the control animals examined shortly before such exposure $(100.0 \pm 2.0 \% ; n=8)$, whilst the values found in the caecum and colon after exposure to the soybean oil-enriched diet $(95.8 \pm 2.8 \% ; \mathrm{n}=12 ; \mathrm{p}>0.2)$ or flaxseed oilenriched diet $(103.3 \pm 4.4 \% ; \mathrm{n}=12 ; \mathrm{p}>0.5)$ failed to differ significantly from the corresponding reference values $(100.0 \pm 2.6 \% ; n=10)$. Likewise, when the $\omega 3 \mathrm{D}$ rats were exposed for 2 or 4-5 weeks to the flaxseed oil-enriched diet, the results collected in the duodenum and jejunum decreased from the reference values $(100.0 \pm 2.7 \% ; n=12)$ to $81.6 \pm 3.9 \%$ $(\mathrm{n}=12 ; \mathrm{p}<0.001)$ after 2 weeks and $65.7 \pm 3.4 \%(\mathrm{n}=12 ; \mathrm{p}<0.001)$ after 4-5 weeks, whilst the values found in the caecum and colon failed to differ significantly from their reference values $(100.0 \pm 3.1 \% ; \mathrm{n}=12)$ whether after 2 weeks $(105.2 \pm 6.0 \%$; $\mathrm{n}=12 ; \mathrm{p}>0.5)$ or $4-5$ weeks $(102.5 \pm 2.7 \% ; \mathrm{n}=12 ; \mathrm{p}>0.5)$. Fig. 3 illustrates the analogy found, in this respect, for the 3 ratios computed in the intestinal phospholipids.

Comparisons, correlations and covariances. Fig. 2 documents that the increase in the fatty acid content of selected fatty acids in the phospholipids of the duodenum and jejunum, as provoked by the flaxseed oil-enriched diet, was quite variable in its relative magnitude. It indeed ranged $(\mathrm{p}<0.001)$ between the extreme values of $6.8 \pm 3.1 \%(\mathrm{df}=42)$ in the case of $\mathrm{C} 18: 1 \omega 9$ and $154.6 \pm 21.7 \%(\mathrm{df}=28)$ in the case of $\mathrm{C} 16: 1 \omega 7$. A further analysis of the present results aimed at identifying factors possibly responsible for such a disparity. For such a purpose, the results recorded in either control animals or $\omega 3 \mathrm{D}$ rats, both exposed for 4-5 weeks to the flaxseed oil-enriched diet, were expressed relative to those found in the control animals shortly before such an exposure. The results obtained in the $\omega 3 \mathrm{D}$ rats after 4-5 weeks exposure to the $\omega 3$-rich diet were also expressed relative to those found in the $\omega 3 \mathrm{D}$ rats shortly before such an exposure.

When examining the results recorded in the duodenum and jejunum, the data obtained for C18:0 were discarded from further consideration because they failed to differ significantly from the reference values found before exposure to the 13 enriched diet. They indeed averaged in the control rats and $\omega 3 \mathrm{D}$ rats, respectively, $98.0 \pm 3.1$ and $94.8 \pm 4.9 \%(n=12$ in both cases) of the mean corresponding reference values $(100.0 \pm 1.6 \% ; n=8)$ recorded in the control animals before exposure to the $\omega 3$-rich diet. Likewise, in the caecum and colon, the results averaged in the control animals and $\omega 3 \mathrm{D}$ rats exposed to the flaxseed oil-enriched diet 109.4 \pm 5.3 and $101.1 \pm 2.6 \%$ ( $\mathrm{n}=12$ in both cases), respectively, of the reference values $(100.0 \pm 3.9 \% ; n=10)$ found in the control animals examined shortly before such an exposure.

In the case of the remaining 7 saturated or monode-

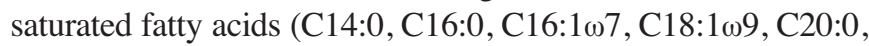
$\mathrm{C} 22: 0$ and $\mathrm{C} 24: 0)$, a highly significant negative correlation $(\mathrm{r}=-0.8445, \mathrm{n}=13 ; \mathrm{p}<0.001)$ was found, in the control animals, between the content of these fatty acids in duodenal and jejunal phospholipids, as found after exposure to the flaxseed oil-enriched diet and as expressed relative to the reference value measured before such an exposure, and the relative weight content of the same fatty acid at the same intestinal level in the control animals examined before exposure to the w3-enriched diet (Fig. 4, left panel). A comparable situation 


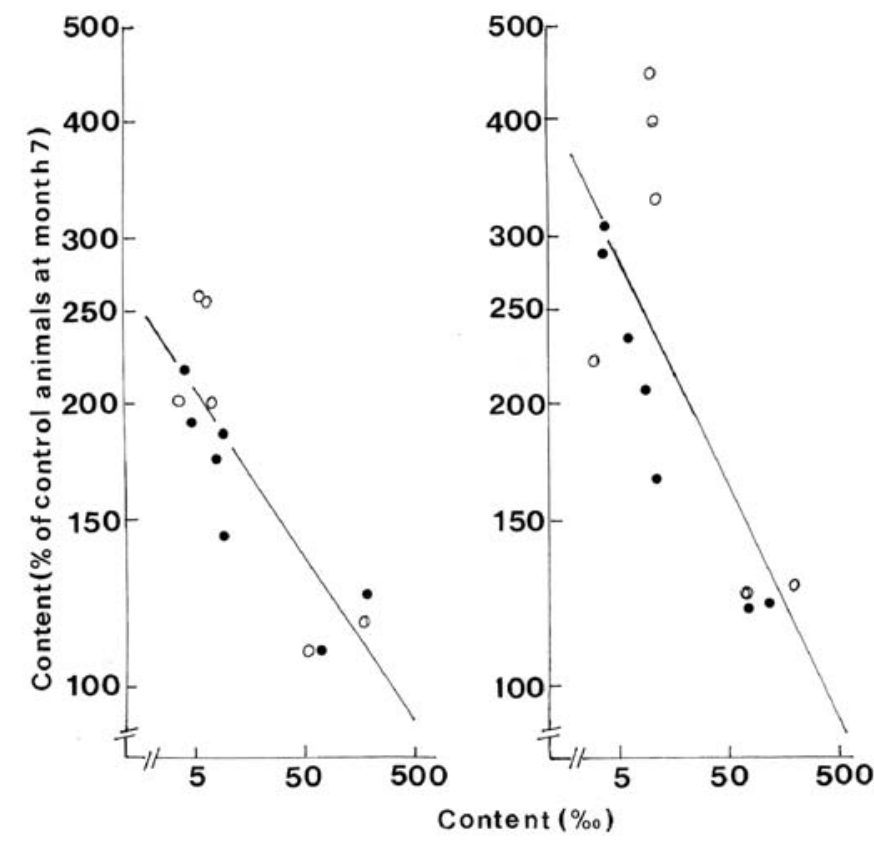

Figure 4. Relationship between the relative content (\%o) of C14:0, C16:0, $\mathrm{C} 16: 1 \omega 7, \mathrm{C} 18: 1 \omega 9, \mathrm{C} 20: 0, \mathrm{C} 22: 0$ and $\mathrm{C} 24: 0$ in the duodenum (closed circles) and jejunum (open circles) of either control animals (left) or $\omega 3 \mathrm{D}$ rats (right) examined 7 months after the start of the experiments and the values found after exposure of either the control animals (left) or $\omega 3 \mathrm{D}$ rats (right) for 4-5 weeks to a flaxseed oil-enriched diet, the latter values being expressed relative to those recorded for the same fatty acid and at the same intestinal level in the control animals again examined at the 7 th month shortly before exposure to $\omega 3$-rich diet. Both variables are ranged on logarithmic scales. The oblique lines correspond to the regression lines.

prevailed in $\omega 3 \mathrm{D}$ rats, all data collected before exposure to the $\omega 3$-enriched diet also concerning $\omega 3 \mathrm{D}$ rats $(\mathrm{r}:-0.8525$; $\mathrm{n}=13 ; \mathrm{p}<0.001$ ). Covariance analysis indicated that the slope of the regression line, established in logarithmic coordinates, was not significantly different in control animals and $\omega 3 \mathrm{D}$ rats. Its elevation was higher $(p<0.025)$, however, in the $\omega 3 \mathrm{D}$ rats than in control animals. This difference was borne out by the fact that the ratio between the values recorded after/before exposure to the flaxseed oil-enriched diet averaged, in the $\omega 3 \mathrm{D}$ rats, $120.1 \pm 6.7 \%$ (geometric mean; $\mathrm{n}=13 ; \mathrm{p}<0.007$ versus unity) of the corresponding values found in control animals. As documented in Fig. 4, a comparable situation prevailed when the phospholipid content after exposure to the 133 enriched diet was expressed, in both control animals and $\omega 3 \mathrm{D}$ rats, relative to the value found in the control animals before such an exposure. Thus, covariance analysis indicated that the slope of the two regression lines drawn in Fig. 4 again failed to differ significantly from one another, while their elevation was higher $(\mathrm{p}<0.01)$ in the $\omega 3 \mathrm{D}$ rats than in the control animals. And, indeed, in this case the values recorded in the $\omega 3 \mathrm{D}$ rats averaged $131.1 \pm 5.0 \%(n=77 ; p<0.001)$ of the mean corresponding values found for the same fatty acid and at the same intestinal level in the control animals (100.0 $\pm 3.2 \%$; $\mathrm{n}=75$ ), all rats being examined after 4-5 weeks exposure to a flaxseed oil-enriched diet.

Another finding emerging from this further analysis and relevant to the enrichment of intestinal phospholipids in selected saturated fatty acids after exposure to the flaxseed oil-enriched diet is documented in Table II. In the case of

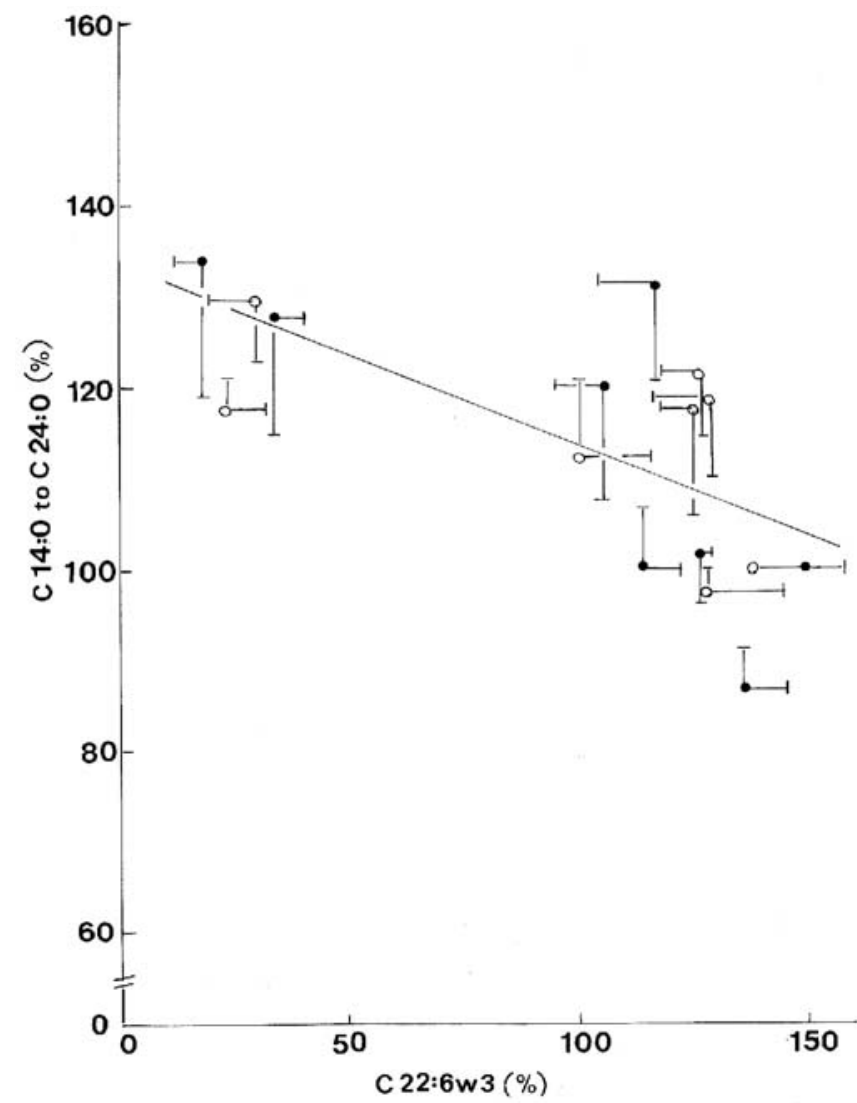

Figure 5. Relationship between the $\mathrm{C} 22: 6 \omega 3$ content and that of saturated

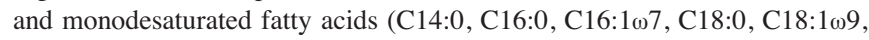
C20:0, C22:0 and C24:0) in the phospholipids of the caecum (closed circles) and colon (open circles) in the 8 groups of rats considered in the present study. Mean values ( \pm SEM) for the C22:6 33 content refer to 5-6 individual measurements, and are expressed relative to the mean value itself derived from the 8 mean values found at the same intestinal level in the 8 groups of rats, i.e. 31.7 and $31.9 \%$ in the caecum and colon, respectively. Mean values $( \pm$ SEM) for the $\mathrm{C} 14: 0$ to $\mathrm{C} 24: 0$ content refer to the 8 different fatty acids under consideration, the mean phospholipid content of each of these 8 fatty acids being expressed relative to corresponding value found at the same intestinal level in the control animals examined 7 months after the start of the present experiments. The oblique line corresponds to the regression line.

C20:0, C22:0 and C24:0, the values found in the intestinal phospholipids of rats exposed for 4-5 weeks to the flaxseed oil-enriched diet and expressed relative to those found for the same fatty acid and at the same intestinal level in the control animals examined before such an exposure were invariably higher in the jejunum than in the duodenum. For instance, in the control rats, the values for C20:0, C22:0 and C24:0, respectively, found in the jejunum averaged 146.7 \pm 7.8 , $138.8 \pm 9.3$ and $140.1 \pm 15.2 \%(n=6$ in all cases $)$ of the corresponding values found in the duodenum. In the $\omega 3 \mathrm{D}$ rats, these percentages amounted to $192.9 \pm 7.8,192.0 \pm 11.6$ and $190.3 \pm 13.4 \%$ ( $n=6$ in all cases). Taking into account the dispersion of data at both intestinal levels, the difference between jejunal and duodenal data averaged, for these 3 fatty acids, $+41.9 \pm 7.5 \%(\mathrm{df}=34 ; \mathrm{p}<0.001)$ in the control animals as distinct $(\mathrm{p}<0.001)$ from $+91.7 \pm 11.1 \%(\mathrm{df}=34 ; \mathrm{p}<0.001)$ in the $\omega 3 \mathrm{D}$ rats. It should be underlined that such a systematic difference between duodenal and jejunal data was not observed for the other saturated or monodesaturated fatty acids. 
Table II. Weight content of saturated and monodesatured fatty acids in the intestinal phospholipids of control and $\omega 3 \mathrm{D}$ rats exposed for 4-5 weeks to a flaxseed oil-enriched diet, expressed relative to the mean corresponding values found in the control animals shortly before such an exposure.

\begin{tabular}{|c|c|c|c|c|c|}
\hline Fatty acid & Rats & Duodenum & Jejunum & Caecum & Colon \\
\hline \multirow[t]{3}{*}{ C14:0 } & $7 \mathrm{mC}$ & $100.0 \pm 0.9(3)$ & $100.0 \pm 15.6(5)$ & $100.0 \pm 22.2(5)$ & $100.0 \pm 12.2(5)$ \\
\hline & $7 \mathrm{mC} / 4 \mathrm{wF}$ & $190.9 \pm 52.3(6)$ & $200.4 \pm 49.3(6)$ & $67.1 \pm 14.2(6)$ & $99.4 \pm 9.0(6)$ \\
\hline & $7 \mathrm{mD} / 4 \mathrm{wF}$ & $307.2 \pm 73.8(6)$ & $221.5 \pm 20.5(6)$ & $81.9 \pm 6.3(6)$ & $102.7 \pm 4.6(6)$ \\
\hline \multirow[t]{3}{*}{ C16:0 } & $7 \mathrm{mC}$ & $100.0 \pm 3.4(3)$ & $100.0 \pm 2.0(5)$ & $100.0 \pm 1.8(5)$ & $100.0 \pm 4.0(5)$ \\
\hline & $7 \mathrm{mC} / 4 \mathrm{wF}$ & $126.1 \pm 3.3(6)$ & $117.2 \pm 5.4(6)$ & $101.0 \pm 3.5(6)$ & $104.8 \pm 7.1(6)$ \\
\hline & $7 \mathrm{mD} / 4 \mathrm{wF}$ & $137.7 \pm 5.2(6)$ & $127.9 \pm 5.4(6)$ & $102.7 \pm 4.5(6)$ & $104.7 \pm 3.7(6)$ \\
\hline \multirow[t]{3}{*}{ 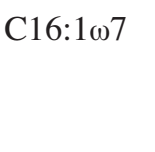 } & $7 \mathrm{mC}$ & $100.0 \pm 7.4(3)$ & $100.0 \pm 10.4(5)$ & $100.0 \pm 4.7(5)$ & $100.0 \pm 13.9(5)$ \\
\hline & $7 \mathrm{mC} / 4 \mathrm{wF}$ & $217.6 \pm 32.2(3)$ & N.D. & $97.3 \pm 14.3(5)$ & $92.0 \pm 2.9(6)$ \\
\hline & $7 \mathrm{mD} / 4 \mathrm{wF}$ & $287.3 \pm 47.7(5)$ & $155.3 \pm 61.4(2)$ & $124.6 \pm 24.4(6)$ & $119.6 \pm 26.8(6)$ \\
\hline \multirow[t]{3}{*}{ C18:0 } & $7 \mathrm{mC}$ & $100.0 \pm 0.8(3)$ & $100.0 \pm 2.6(5)$ & $100.0 \pm 3.7(5)$ & $100.0 \pm 7.4(5)$ \\
\hline & $7 \mathrm{mC} / 4 \mathrm{wF}$ & $90.0 \pm 2.0(6)$ & $106.0 \pm 3.5(6)$ & $111.4 \pm 6.6(6)$ & $107.4 \pm 8.9(6)$ \\
\hline & $7 \mathrm{mD} / 4 \mathrm{wF}$ & $87.7 \pm 6.1(6)$ & $101.9 \pm 6.8(6)$ & $100.1 \pm 4.0(6)$ & $102.0 \pm 3.7(6)$ \\
\hline \multirow[t]{3}{*}{ 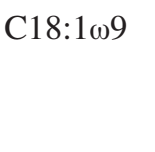 } & $7 \mathrm{mC}$ & $100.0 \pm 2.5(3)$ & $100.0 \pm 6.3(5)$ & $100.0 \pm 4.4(5)$ & $100.0 \pm 10.0(5)$ \\
\hline & $7 \mathrm{mC} / 4 \mathrm{wF}$ & $109.9 \pm 3.3(6)$ & $109.8 \pm 6.3(6)$ & $95.7 \pm 3.5(6)$ & $102.0 \pm 5.7(6)$ \\
\hline & $7 \mathrm{mD} / 4 \mathrm{wF}$ & $121.3 \pm 5.2(6)$ & $125.7 \pm 4.9(6)$ & $103.6 \pm 2.9(6)$ & $110.5 \pm 6.3(6)$ \\
\hline \multirow[t]{3}{*}{ C20:0 } & $7 \mathrm{mC}$ & $100.0 \pm 8.0$ & $100.0 \pm 9.7(5)$ & $100.0 \pm 4.8(5)$ & $100.0 \pm 11.1(5)$ \\
\hline & $7 \mathrm{mC} / 4 \mathrm{wF}$ & $174.6 \pm 12.7(6)$ & $256.2 \pm 13.6(6)$ & $122.9 \pm 14.1(6)$ & $154.9 \pm 21.3(6)$ \\
\hline & $7 \mathrm{mD} / 4 \mathrm{wF}$ & $206.2 \pm 36.7(6)$ & $397.9 \pm 16.1(6)$ & $136.2 \pm 34.1(6)$ & $144.4 \pm 16.4(6)$ \\
\hline \multirow[t]{3}{*}{$\mathrm{C} 22: 0$} & $7 \mathrm{mC}$ & $100.0 \pm 10.0$ & $100.0 \pm 9.7(5)$ & $100.0 \pm 2.4(5)$ & $100.0 \pm 7.8(5)$ \\
\hline & $7 \mathrm{mC} / 4 \mathrm{wF}$ & $145.5 \pm 10.8(6)$ & $201.9 \pm 13.6(6)$ & $121.6 \pm 12.2(6)$ & $143.8 \pm 17.4(6)$ \\
\hline & $7 \mathrm{mD} / 4 \mathrm{wF}$ & $174.1 \pm 28.3(6)$ & $334.2 \pm 20.2(6)$ & $196.6 \pm 40.0(6)$ & $152.0 \pm 9.2(6)$ \\
\hline \multirow[t]{3}{*}{$\mathrm{C} 24: 0$} & $7 \mathrm{mC}$ & $100.0 \pm 13.2(3)$ & $100.0 \pm 14.2(5)$ & $100.0 \pm 27.5(5)$ & $100.0 \pm 6.0(5)$ \\
\hline & $7 \mathrm{mC} / 4 \mathrm{wF}$ & $185.8 \pm 16.7(6)$ & $260.3 \pm 28.2(6)$ & $82.9 \pm 10.1(6)$ & $146.5 \pm 18.3(6)$ \\
\hline & $7 \mathrm{mD} / 4 \mathrm{wF}$ & $235.5 \pm 40.6(6)$ & $448.3 \pm 31.6(6)$ & $117.6 \pm 12.6(6)$ & $137.8 \pm 17.2(6)$ \\
\hline
\end{tabular}

N.D., Not determined.

At variance with the findings made in the duodenum and jejunum, no significant correlation $(p>0.1)$ was found in the caecum and colon between the relative weight content of

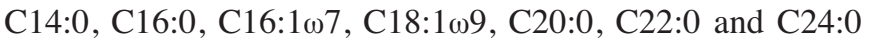
found in the phospholipids of rats exposed for 4-5 weeks to the $\omega 3$-enriched diet and expressed relative to the mean corresponding value found for the same fatty acid at the same intestinal level in the control animals examined shortly before such an exposure, on one hand, and the absolute values for the relative weight content of the same fatty acids at the same intestinal level in the control animals also examined before exposure to the flaxseed oil-enriched diet, on the other hand. Thus, the correlation coefficient between these two variables did not exceed -0.0830 and -0.4395 ( $n=14$ in both cases) in control animals and $\omega 3 \mathrm{D}$ rats, respectively.

Pooling all available data collected in the caecum and colon of control rats exposed for 4-5 weeks to the flaxseed oil-enriched diet, the phospholipid content in C14:0, C16:0,

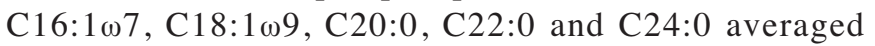
$109.4 \pm 4.0 \%(\mathrm{n}=84 ; \mathrm{p}<0.08)$ of the mean corresponding values found for the same fatty acids at the same intestinal level in the control animals examined shortly before such an exposure $(100.0 \pm 2.8 \% ; n=70)$. Such an increase $(+9.4 \pm 5.1 \%$; $\mathrm{df}=152$ ), which indeed failed to achieve statistical significance, was lower $(p<0.01)$ than that recorded in the duodenum and jejunum $(+31.1 \pm 6.0 \%$; $\mathrm{df}=150)$. Moreover, when considering separately the results obtained in the caecum or colon with $\mathrm{C} 14: 0, \mathrm{C} 16: 0, \mathrm{C} 16: 1 \omega 7$ and $\mathrm{C} 18: 1 \omega 9$ on one hand and C20:0, $\mathrm{C} 22: 0$ and $\mathrm{C} 24: 0$ on the other hand, a significant difference $(+48.4 \pm 12.2 \% ; \mathrm{df}=31 ; \mathrm{p}<0.001)$ was only found for the C20:0, C22:0 and C24:0 phospholipid content in the colon.

Likewise, pooling all available data collected in the caecum and colon, the values recorded in the $\omega 3 \mathrm{D}$ rats exposed for $4-5$ weeks to the $\omega 3$-enriched diet remained higher $(114.9 \pm 4.7 \%$; $\mathrm{n}=84 ; \mathrm{p}<0.03$ ) than the corresponding values found at the same intestinal level in the control animals exposed for the same time to the same diet $(100.0 \pm 2.8 \% ; n=84)$. Such an increase $(+14.9 \pm 5.4 \%$; $\mathrm{df}=166)$ was lower, albeit not significantly so $(\mathrm{p}>0.1)$, than that observed in the caecum and colon when comparing $\omega 3 \mathrm{D}$ rats to control animals before 
exposure to the $\omega 3$-enriched diet $(+28.4 \pm 7.5 \%$; $\mathrm{df}=151)$. Moreover, when considering separately the results obtained in the caecum or colon with $\mathrm{C} 14: 0, \mathrm{C} 16: 0, \mathrm{C} 16: 1 \omega 7$ and $\mathrm{C} 18: 1 \omega 9$ on one hand and $\mathrm{C} 20: 0, \mathrm{C} 22: 0$ and $\mathrm{C} 24: 0$ on the other hand, a significant difference $(+38.1 \pm 16.3 \%$; $\mathrm{df}=34 ; \mathrm{p}<0.03)$ was only found for the phospholipid C20:0, C22:0 and C24:0 content in the caecum.

No obvious relationship was found between the relative increase in the content of fatty acids in duodenal and jejunal phospholipids, as caused by exposure to the flaxseed oilenriched diets and the relative content of the same fatty acids in the lipids of such diets. Actually, the weight percentages

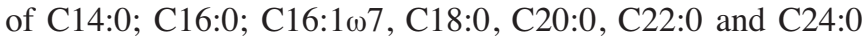
in the lipids of these diets were all lower than those found in the duodenal and jejunal phospholipids of the control animals examined 7 months after the start of the present experiments. Only the weight percentage of C18:1w9 (17.1-19.5\%) was higher in the lipids of the flaxseed oil-enriched diets than in the duodenal and jejunal phospholipids of the latter control animals (5.3-6.2\%). Yet, as documented in Figs. 1 and 2, the relative increase of the duodenal and jejunal phospholipid content in C18:1w9 resulting from exposure to the flaxseed oil-enriched diets was much less marked than that observed with all other saturated and monodesaturated fatty acids (at the exclusion of C18:0).

Fig. 5 illustrates the negative correlation $(r=-0.6503 ; n=16$; $\mathrm{p}<0.008$ ) found in the distal segments of the intestinal tract between the mean content of all saturated and monodesaturated fatty acids considered in this study in the 8 groups of rats examined in this work, expressed relative to the corresponding value found for the same fatty acid (C14:0, C16:0, C16:167, $\mathrm{C} 18: 0, \mathrm{C} 18: 1 \omega 9, \mathrm{C} 20: 0, \mathrm{C} 22: 0$ or $\mathrm{C} 24: 0)$ at the same intestinal level (caecum or colon) in the control animals sacrificed 7 months after the onset of the present experiments, on one hand, and the mean $\mathrm{C} 22: 6 \omega 3$ content of phospholipids found in each of the same 8 groups of rats, expressed relative to the overall mean value found in these 8 groups of rats in either the caecum or colon, on the other hand. As could be expected from findings such as those illustrates in Figs. 1 and 2, no significant correlation between the same two variables $(\mathrm{r}=+0.3456 ; \mathrm{n}=14 ; \mathrm{p}>0.1)$ was observed when the same analytical procedure was conducted in the proximal segments of the intestinal tract, i.e. in the duodenum and jejunum. Covariance analysis confirmed that the slope of the regression line was significantly different $(\mathrm{p}<0.05)$ in the proximal $(+0.3003)$ and distal $(-0.2014)$ segments of the intestinal tract.

\section{Discussion}

The relative content of saturated and/or monodesaturated in intestinal mucosal phospholipids does not represent a negligible item in the physiopathology of the intestinal tract. To cite only one example, Pajari and Mutanen (7) drew attention to the fact that, in male Wistar rats fed on diets containing butter or coconut-oil at energy levels of $10 \%$ and $43 \%$ for 4 weeks, a positive correlation prevailed between the proportion of C14:0 and C18:0 in caecal phospholipids and membrane protein kinase $\mathrm{C}$ activity. Yet, several environmental factors may affect the intestinal phospholipid content of such saturated and/or monodesaturated fatty acids. For instance, Waheed et al (8) documented that, in starved rats, the percentage of C18:0 was increased and that of C18:109 decreased in small intestine brush border membrane lipids. Likewise, Keelan et al (9) investigated the alteration of lipid composition in the enterocyte brush border membrane resulting from isocaloric modifications for 2 weeks in the type of lipids present in the diet offered to adult rats. The activity of $\Delta 5$ desaturase was found to be higher in rats fed a diet with triglycerides enriched with polyunsaturated, as distinct from saturated, fatty acids. Keelan et al (10) also observed that, in female Wistar rats fed for 8 weeks a high saturated fatty acid diet enriched with C16:0, C18:0 and C18:1w9, phospholipid fatty acid changes, which were more pronounced in the jejunal than ileal brush border membrane, consisted mainly in an increase of total monosaturated fatty acids (such as C18:1w9) and decrease of total polyunsaturated fatty acids, especially $\omega 6$ fatty acids. In respect to regional differences in lipid composition, Garg et al (11) reported higher levels of C18:0 but lower levels


phospholipids, this coinciding with higher incorporation of $\left[1-{ }^{14} \mathrm{C}\right]$ palmitate $(\mathrm{C} 16: 0)$ in jejunal, as compared to ileal, microsomal membranes.

The present study affords four major pieces of information: First, it extends to saturated and monodesaturated fatty acids the knowledge, recently documented in the same rats for longchain polyunsaturated $\omega 3$ and $\omega 6$ fatty acids $(1,2)$, that their relative abundance in phospholipids, as well as the ratio between selected fatty acids, may differ vastly at distinct intestinal levels. Except in the case of C18:0, the relative weight content of the saturated and monodesaturated fatty acids in intestinal phospholipids is lowest in the duodenum and jejunum and highest in the colon, with in-between values in the caecum. Such is also the case for the precursors of

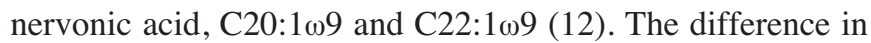
the phospholipid fatty acid pattern in distinct intestinal segments could conceivably be related, in part at least, to the production of short-chain fatty acids by fermentation of the colic intestinal flora, leading to the promotion of longer fatty acid synthesis in colonocytes.

Second, this study documents changes in both the relative weight content of saturated and monodesaturated fatty acids in intestinal phospolipids and the ratio between some of these fatty acids as resulting from a dietary deprivation of long-chain polyunsaturated $\omega 3$ fatty acids. Such changes were often already evident after only 3 months of $\omega 3$-deprivation. They consisted, for all fatty acids under consideration in this study, in an increase of the relative weight content above the corresponding values found in control animals. Once again, such an increase was also observed in the case of C20:1 09 and C22:1 199 (12). It cannot be solely attributed to the lower content of long-chain polyunsaturated $\omega 3$ fatty acids in the $\omega 3 \mathrm{D}$ rats, as indicated for instance by its quite variable relative magnitude. For instance and as illustrated in Fig. 2, during the first 7 months of the present experiments, the intestinal phospholipid content of $\mathrm{C} 16: 0$ was increased, in the $\omega 3 \mathrm{D}$ rats, by no more than $6.3 \pm 2.9 \%(\mathrm{df}=76)$, as compared $(\mathrm{p}<0.003)$ to an increase of $48.3 \pm 13.1 \%(\mathrm{df}=76)$ for $\mathrm{C} 16: 1 \omega 7$.

Third, the eventual exposure of either the control animals or $\omega 3 \mathrm{D}$ rats to a soybean or flaxseed oil-enriched diet again 
affected the relative content of and ratio between selected saturated and monodesaturated fatty acids. In this respect, it should be underlined that, in the $\omega 3 \mathrm{D}$ rats exposed to the flaxseed oil-enriched diet, the observed changes did not always consist in a move towards normal values. On the contrary, the abnormally high values found for the relative content of saturated and monodesaturated fatty acids found in the $\omega 3 \mathrm{D}$ rats further increased, as a rule, during exposure to this $\omega 3$-enriched diet.

Last, the latter increase, which was also recorded in control animals, was as a rule, more pronounced in the proximal segments of the intestinal tract than in the more distal ones. The sole exception to such a finding concerning C18:0, in which case the values recorded after 4-5 weeks exposure to the flaxseed oil-enriched diet and expressed relative to the mean corresponding values recorded at the same intestinal level in the rats examined shortly before such an exposure were, in control animals and $\omega 3 \mathrm{D}$ rats, lower in the duodenum and jejunum than in the caecum and colon. The latter difference remained significant $(\mathrm{p}<0.04)$ when the results recorded in both the control animals exposed for 4-5 weeks to the soybean oil-enriched diet and the $\omega 3 \mathrm{D}$ rats exposed for only 2 weeks to the flaxseed oil-enriched diet were also taken into account $(92.7 \pm 1.7 \%$ in duodenum and jejunum versus $99.4 \pm 2.6 \%$ in caecum and colon; $n=48$ in both cases).

The increase in the saturated and monodesaturated fatty acid content of intestinal phospholipids, as observed after exposure of the rats to the soybean or flaxseed oil-enriched diets, cannot be blamed solely on a high content of these fatty acids in these diets. Thus, C18:1 199 was the sole of these fatty acids with a higher relative content in the lipids of these diets (17.1-19.5\%) than in the intestinal phospholipids of control or $\omega 3 \mathrm{D}$ rats $(5.4-12.8 \%)$. It should be stressed, however, that the soybean and flaxseed oil-enriched diets presented a total lipid content $(10 \%, w / w)$ twice higher than the control and $\omega 3$-deprived diets given during the first 7 months of the present experiments and containing only $5 \%(\mathrm{w} / \mathrm{w})$ soybean or sunflower oil. This difference may well participate in the enrichment of intestinal phospholipids in selected fatty acids, especially at the proximal levels of the intestinal tract (duodenum and jejunum).

With these considerations in mind, the results recorded at the most distal levels of the intestinal tract (caecum and colon) may well be more relevant than those recorded in the duodenum and jejunum to the relationship between changes in the availability of long-chain polyunsaturated $\omega 3$ fatty acids and the pattern of other fatty acids, e.g. saturated and monodesaturated fatty acids, in intestinal phospholipids. The latter proposal is supported by the finding of a significant inverse correlation at the distal (but not proximal) intestinal sites between the $\mathrm{C} 22: 4 \omega 6$ content of phospholipids and the relative content of the 8 fatty acids under consideration in the present study in the 8 groups of rats here also under consideration.

\section{Acknowledgements}

This study was supported by a grant from the Belgian Foundation for Scientific Medical Research (3.4574.07), and by Convention 5459 (Project WALNUT-20) from the Région Wallonne (Namur, Belgium). We are grateful to A. Chwalik and A. Dufour for technical assistance, and C. Demesmaeker for secretarial help.

\section{References}

1. Hacquebard M, Portois L, Malaisse W and Carpentier YA: The metabolic syndrome of $\omega 3$-depleted rats. IV. Intestinal phospholipid $\omega 3$ fatty acids. Int J Mol Med 24: 859-865, 2009.

2. Hacquebard M, Portois L, Malaisse WJ and Carpentier YA: The metabolic syndrome of $\omega 3$-depleted rats. V. Intestinal phospholipid $\omega 6$ fatty acids. Int J Mol Med 24: 867-875, 2009

3. Malaisse WJ, Bulur N, Zhang Y, Hacquebard M, Portois L, Sener A and Carpentier YA: The metabolic syndrome of $\omega 3$ depleted rats. I. Liver data. Int J Mol Med 24: 111-123, 2009.

4. Folch J, Lees M and Sloane-Stanley GH: A simple method for the isolation and purification of total lipids from animals tissues. J Biol Chem 226: 497-509, 1957.

5. Dahlan W, Richelle M, Kulapongse S, Rössle C, Deckelbaum RJ and Carpentier YA: Effects of essential fatty acid contents of lipid emulsions on erythrocyte polyunsaturated fatty acid composition in patients on long-term parenteral nutrition. Clin Nutr 11: 262-268, 1992.

6. Lepage G and Roy CC: Direct transesterification of all classes of lipids in one step reaction. J Lipid Res 27: 114-120, 1986.

7. Pajari AM and Mutanen N: Phospholipid fatty acid composition and protein kinase $\mathrm{C}$ activity in the large intestine of rats fed on butter and coconut-oil diets. Br J Nutr 82: 411-418, 1999.

8. Waheed AA, Yasuzumi F and Gupta PD: Lipid and fatty acid composition of brush border membrane of rat intestine during starvation. Lipids 33: 1093-1097, 1998

9. Keelan M, Clandinin MT and Thomson AB: Dietary lipids influence the activity of delta 5-desaturase and phospholipid fatty acids in rat enterocyte microsomal membranes. Can J Physiol Pharmacol 75: 1009-1014, 1997.

10. Keelan M, Wierzbicki A, Clandinin MT, Walker K and Thomson AB: Alterations in dietary fatty acid composition alter rat brush border membrane phospholipid fatty acid composition. Diab Res 14: 165-170, 1990.

11. Garg ML, Keelan M, Wierzbicki A, Thomson AB and Clandinin MT: Regional differences in lipid composition and incorporation of saturated and unsaturated fatty acids into microsomal membranes of rat small intestine. Can J Physiol Pharmacol 66: 794-800, 1988.

12. Malaisse WJ, Portois L, Hacquebard M and Carpentier YA: The metabolic syndrome of $\omega 3$-depleted rats. VII. Intestinal phospholipid 19 fatty acids. Met Funct Res Diab (In press). 